\title{
KH. Ahmad Sanusi dan Karya-Karyanya: Khasanah Literasi Ilmu-Ilmu Ajaran Islam di Nusantara
}

\author{
KH. Ahmad Sanusi and his Works: Literacy Treasures of Islamic Studies \\ in the Archipelago
}

\author{
Munandi Saleh \\ Sekolah Tinggi Islam (STAI) Syamsul 'Ulum Gunungpuyuh \\ Sukabumi, Jawa Barat, Indonesia \\ Munandisaleh66@gmail.com
}

\begin{abstract}
Abstrak
KH Ahmad Sanusi menulis sekitar tahun 1914 sampai dengan tahun 1950. Tulisan ini bertujuan untuk mengungkap hasil buah karya K.H. Ahmad Sanusi. Jenis penelitian ini adalah kualitatif yang bersifat studi pustaka (library research). Sumber data ada dua macam yaitu sumber primer yang menjadi referensi utama dan sumber sekunder yang merupakan referensi-referensi pendukung dan pelengkap. Metode yang digunakan untuk mengumpulkan data penelitian berupa data-data kepustakaan yang kemudian dianalisis dengan teknik analisis isi (content analysis). Berdasarkan penelusuran literatur, pada tahun 1914 sampai dengan tahun1942, K.H. Ahmad Sanusi menulis kitab tidak kurang dari 126 judul kitab, pada tahun 1946, karya K.H. Ahmad Sanusi telah mencapai hampir 200 judul kitab, dan pada tahun 1950, sebelum Ia meninggal dunia berdasarkan pengakuan keluarganya hasil karyanya telah mencapai sekitar 480 judul kitab. Berdasarkan hasil penelitian tersebut dapar disimpulkan bahwa K.H. Ahmad Sanusi adalah seorang penulis nusantara yang produktif
\end{abstract}

Kata kunci: Ahmad Sanusi, Karya-Karya, Khasanah, Literasi, Nusantarta.

\section{Abstract}

KH Ahmad Sanusi wrote around 1914 until 1950. This research aims to explain the works of K.H. Ahmad Sanusi. This kind of research was qualitative with library research. There are two kinds of data sources, namely primary sources which were the main references and secondary sources which were supporting and complementary references. The method to collect research data in the form of library data which was analyzed by content analysis techniques. Based on literature, in 1914 to 1942 K.H. Ahmad Sanusi wrote the book no less than 126 titles of the book. Then in 1946, K.H. Ahmad Sanusi has reached nearly 200 titles of the Book, finally in 1950, before he died, based on the recognition of his family the results of his works had reached around 480 titles. Based on results of reseach, can be concluded that K.H. Ahmad Sanusi is a writer of Indonesian archipelago productivly.

Keywords: Ahmad Sanusi, Works, Khasanah, Literacy, Indonesian Archipelago. 


\section{PENDAHULUAN}

Kiayi Haji Ahmad Sanusi seorang putera Sukabumi yang pernah berkiprah di panggung nasional di era 1920-an sampai dengan 1950-an. Ia adalah seorang Ulama Pemikir dan Pejuang yang telah menorehkan tinta emas dalam sejarah perjuangan kemerdekaan Republik Indonesia. Ia dilahirkan pada tanggal 12 Muharram $1306 \mathrm{H}$ bertepatan dengan tanggal 18

September 1888 M di Kampung Cantayan Desa Cantayan Kecamatan Cantayan Kabupaten Sukabumi (Daerah tersebut duhulunya bernama Kampung Cantayan Desa Cantayan Onderdistrik Cikembar, Distrik Cibadak, Afdeeling Sukabumi) anak ketiga dari delapan bersaudara pasangan K.H. Abdurrohim (Ajengan Cantayan, Pimpinan Pondok Pesantren Cantayan) dengan Ibu Empok (Saleh, 2016). Ahmad Sanusi dalam memperjuangkan pemikiran dan gagasannya untuk kepentingan Agama, Bangsa dan Negara aktif dalam berbagai lembaga dan kegiatan baik sebagai pendiri dan pelaku maupun sebagai pelaksana, diantaranya: menjadi anggota BPUPKI (Dokuritsu Junbi Cosakai), Pengurus Jawa Hokokai (Kebangkitan Jawa), Pengurus Masyumi (Majelis Syuro' Muslimin Indonesia), anggota KNIP (Komite Nasional Indonesia Pusat), anggota Dewan Penasehat Daerah Bogor (Giin Bogor Shu Sangi Kai), Wakil Residen Bogor (Fuku Syucokan), bahkan di wilayah Keresidenan Bogor (Bogor Syu), Ahmad Sanusi membidani lahirnya : Tentara PETA (Pembela Tanah Air), BKR (Badan Keamanan Rakyat), KNID (Komite Nasional Indonesia Daerah), juga ia menjadi Ketua Umum Pengurus Besar AII (POII atau PUII), Instruktur pada Pelatihan Ulama yang diselenggarakan oleh pemerintah militer Jepang serta 
menjadi Pendiri Pondok Pesantren

Genteng, Pondok Pesantren

Gunungpuyuh,

Organisasi

anderbouw AII, seperti BII, Zaenabiyyah, IMI, pendiri GUPPI (Gabungan Usaha-usaha Perbaikan Pendidikan Islam), dll.

Sebagai pengahrgaan atas jasa-jasnya Pemerintah Republik Indonesia mengangkatnya menjadi salah seorang

perintis

Kemerdekaan Republik Indonesia.

Pada tanggal 12 Agustus 1992

Presiden Soeharto menganugerahi penghargaan Bintang Maha Putera Utama dan Presiden Susilo Bambang Yudoyono menganugerahi Bintang Maha Putera Adipradana pada tanggal 10 November 2009. Pemerintah Kota

Sukabumi mengabadikan namanya menjadi salah satu nama jalan di Kota Sukabumi, yang menghubungkan antara jalan Cigunung sampai dengan Degung dan Nama Terminal Type A yang berada di Jalan Jalur
Lingkarselatan Kota Sukabumi. Gubernur Jawa Barat Bapak Dr.H. Ahmad Heriawan, Lc, M.Si mengabadikan Karya Ahmad Sanusi yang monumental yakni Tafsir Raudhatul Irfan menjadi nama Masjid Raya Raudhatul Irfan, sebuah Masjid yang dibangun oleh Pemerintah Provinsi Jawa Barat yang berada di Jalan Lingkar Selatan Cibolang Sukabumi. Sedangkan keluarga mengabadikan namanya menjadi nama sebuah Gedung Auditorium yang berada di kompleks Pondok Pesantren Syamsul'Ulum Gunungpuyuh Sukabumi.

Sebuah hikmah dari 15 bulan di penjara dan 11 tahunan di internir (dibuang) dengan status tahanan kota, KH Ahmad Sanusi menjadi seorang penulis yang produktif. KH. Ahmad Sanusi selain melahirkan para santri menjadi kiayi dan mewariskan lembaga pendidikan dan organisasi kemasyarakatan yang menjadi alat 
perjuangan, pendidikan dan

Dakwah, Ia juga melahirkan bayak karya tulis yang jumlahnya ratusan ia wariskan kepada gererasi berikutnya. Tidak kurang dari 126 judul kitab yang ia tulis dari berbagai disiplin keilmuan, diantaranya Tafsir al-Qur'an, Ilmu Tauhid, Ilmu Fiqih, Ma'ani, Bayan, dll. Unruk mengatahui lebih mendalam, penelitian ini ditujukan untuk menelusuri karya-karya $\mathrm{KH}$ Ahmad Sanusi sebagai bagian dari khasanah literasi ilmu-ilmu ajaran Islam di nusantara.

\section{METODE PENELITIAN}

Penelitian ini adalah penelitian kualitatif yang bersifat studi pustaka (library research) yang menggunkan buku-buku dan literatur-literatur lainnya sebagai objek yang utama (Hadi, 1995). Sebagai penelitian kepustakaan, sumber data ada dua macam yaitu 1) Sumber primer yang merupakan suatu referensi yang dijadikan sumber utama acuan penelitian. 2)
Sumber sekunder yang merupakan referensi-referensi pendukung dan pelengkap bagi sumber primer.

Dalam penelitian kepustakaan, metode yang digunakan untuk mengumpulkan data penelitian berupa data-data kepustakaan yang telah dipilih, dicari, disajikan dan dianalisis. Pengumpulan data yang dilakukan dalam penelitian ini adalah dengan mengumpulkan buku-buku tentang KH. Ahmad Sanusi. Kemudian dipilih, disajikan dan dianalisis serta diolah supaya ringkas dan sistematis. Adapun teknik analisi data dalam penelitian ini berupa analisis isi (content analysis) yaitu analis ilmiah tentang isi pesan suatu data (Muhadjir, 1998).

\section{HASIL}

DAN

\section{PEMBAHASAN}

\section{A. Awal Penulisan Karya- Karyanya}

Ahmad Sanusi, mengawali menulis pada tahun 1914, yakni pada saat ada serangan surat kaleng 
yang beredar di Mekkah alMukkaromah dengan isinya menjelek-jelekkan organisasi Syarikat Islam, disinyalir dibuat oleh Sayyid Utsman bin Abdullah Mufti Batawi (https://en.wikipedia.org, 2018) teman dekatnya Christiaan Snouck Hurgronje

(https://id.wikipedia.org, 2018) atas sokongan Pemerintah Kolonial Belanda (Iskandar, 2001), maka Ahmad Sanusi yang pada saat itu baru sekitar satu tahunan menjadi anggota Syarikat Islam (Mawardi, 2011), tampil untuk membela Syarikat Islam yang isi pembelaannya, selama yang sesuai dengan isi Satatuen (Anggaran Dasar) Syarikat Islam.

Selanjutnya, sepulangnya dari Makkah al-Mukarrmaah pada bulan Juli 1915, K.H. Ahmad Sanusi, selain Ia mengabdi dengan mengajar di Pondok Pesantren Cantayan pimpinan ayahnya K.H. Abdurrahim, juga ia mulai fokus belajar menulis seperti halnya ulama-ulama pendahulunya seperti Syeikh Abdurrouf Singkel, Syeikh Nawawi al-Bantani,dll. Beberapa kitab yang ia tulis ketika di Pondok Pesantren Cantayan selain dari Ilmu Tauhid juga Ilmu-ilmu lain yang nanti akan penulis sampaikan dalam tulisan makalah ini.

\section{B. Karya-Karya K.H. Ahmad Sanusi Berdasarkan Tahun dan Tempat Penulisannya \\ K.H. Ahmad Sanusi, ia} adalah penulis Produktif Nusantara yang telah menghasilkan ratusan karya dalam kurun waktu antara tahun 1914 s.d. tahun 1950. Adapun buah karya yang ia tulis, diantaranya :

1. Sekitar tahun 1914 di Makkah al-Mukarramah pertama kali ia menulis Kitab : Nahratu Dargham; (Suara Singa Wilayah).

2. Pada Tahun 1915-1921 sewaktu di Pesantren Cantayan, ia 
menulis beberapa kitab, diantaranya :

- Lu Lu an-Nadid fi Masail atTauhid;

- 'Uquudu al-Fakhiirah Fii Mustahaadhoti wa alMutahayyiroh (1920);

- Ti'janul Gilmaan Fii Tafsiiril Qur'an Bilughoti asSundawi, Juz ke-30;

- Daliilu as-Saairiina Fii Fadhli ash-Sholaati 'Alaa Sayyidi al-Mursaliin (Nuduhkeun ka sakabeh jalma anu leumpang mapay perjalanan akhirat dina mertelakeun kautamaan maca shalawat ka gustina sakabeh Rasul);

- Hilyatu ash-Shibyaani Fii Bayaani Shaumi Romadhoon;

- Jauharotu al-Mardiyyah Fii Mukhtashor al-Furu'i asySyafi'iyyah.
3. Pada Tahun 1921-1927 sewaktu di Pesantren Babakan Sirna Genteng, ia menulis beberapa kitab, diantaranya:

- Hilyatul 'Aqli wal Fikri Fii Bayani MuqtadhiyatisySyirki wal Kufri (Dandanan Aqal jeung Fikir dina nerangkeun kana rupa-rupa anu matak Musrik jeung Kufur);

- Al-'Aqidatul Islamiyyah Fii Tarjamatir Risalatil Qudsiyyah (Katerangan Aqidahna jalma Islam Dina nerjemahkeun Kitab Risalah Qodsiyyah Karangan Imam Ghazali);

- Hilyatul Iiman Fii Fadhiilati Qirooatil Qur'an (Ngadangdangan Iman di jerona nerangkeun kana ka Utamaan Maca Qur'an), (Ditulis tammat pada poe Jum'at 6 Ramadhan 1342 H/11 Apr 1924 M); 
- Jauhaaru al-Bahiyyati Fii Adaabi al-Mar'ati alMutazawwajati (Pirangpirang Inten anu kacida alusna nerangkeun kana adab-adabannana awewe anu baroga salaki)(Rebo, 22 Syawal 1343 H/15 Mei 1925 M);

- Ti'janul Gilmaan Fii Tafsiiril Qur'an, Juz ke-2;

- Tamsiyyatul Wildan Fii Tafsiiril Qur'an (Surat WadDhuha Alhakumuttakaasyur);

- Tafriiju Quluubil Mu'miniin Fii Tafsiiri Kalimaati Surat Yaasin (Ngabungahkeun kana sakabeh hatena jalma Mu'min Nerangkeun dina kana tafsirna kalimat-kalimat surat Yasiin);

- Siraajul Mu’miniin Fii Ad'iyyati Suraatu Yaasin (Damarna sakabeh mu'min dina nerangkeun kana Du'adu'a Surat Yaasin);

- Hidaayatu Quluubi ashShibyaani Fii Fadlooili Surat Tabaaroka al-Mulka Minal Qur'an (Buat pituduh kasakabeh hatena sakabeh budak Nerangkeun kana pirang-pirang Fadlilahna Surat Tabarak al-Mulka dina Qur'an);

- Tanbiihul Hairaan Fii Tafsiiri Suraatu ad-Dukhaan (Mere inget ka jalma anu bingung dina nerangkeun tafsirna Surat Dukhan);

- Kanzul Rahmah Wal Luthfi Fii Suraati al-Kahfi (Gudangna rahmat jeung ka nyaah nerangkeun kana tafsirna surat Kahfi);

- Kasyfus Sa'aadah Fii Tafsiiri Suraatil Waaqi'ah (Ngabukakeun kabagyaan nerangkeun kana tafsirna surat Waqi'ah); 
- Al-Kawakibu ad-Dariyyah Fii Ad'iyati an-Nabawiyah (Pirang-pirang bentang anu moncorong nerangkeun kana pirang-pirang du'ana kanjeng Nabi SAW);

- Sirooju al-Afkaar Fiima waroda min adzkaari al-Laili wa an-Nahaari (Damarna fikiran anu nerangkeun kana rupa-rupa Dzikir wiridan peuting jeung berang);

- Qolaaidu ad-Darori Fii Bayaani 'Iqdi al-Jauhar (Nerangkeun kana hikayathikayatna dipedalkeun kanjeung Nabi jeung saterasna nepi ka pupusna);

- Hidayatu al-Adzkiyaa Lii Thoriiqoti al-Uliyaa Lii Syeikh Zainuddin Ibnu Ali alMa'barii;

- Matan Nadhom Yaquulu;

- Nadhom Imriti;

- Al-Juz'u al-Awal min Majmuи'ati Duruusu al-
'Uluum (Juz kahiji tina tempat kumpul pangajaranpangajaran rupa-rupa ilmu\};

4. Tahun 1928-1934, sewaktu ia di internir (dibuang) ke Batavia Centrum, ia menulis beberapa kitab, diantaranya :

- Tasyqiiqu al-Auhaam Fii arRad'i 'Ani Thughaam (Meupeujeuh sakabeh persangkaan anu salah dina nyeugah tina sakabeh jalma anu tukang nyasarkeun ka anu barodo) (Tammat poe Sabtu, tanggal 27 Jumadil Ula 1347 H/10 November 1928 M, di Gang Kampoeng Bali Ketjil No.6 Tanah Abang Welteeureon Batavia Centrum);

- Ar-Rud'iyyah fii Majwibda'i adh-Dhawaabit alQonthuuriyyah. Kantor Cetak dan Toko Kitab alIttihad, Tanah Tinggi Batavia, t.t. 
- Al-Fiqhu al-Akbar Li alImaami al-'Adhom Abii Hanifah an-Nu'man (Fiqih anu Agung pikeun karya Imam anu Agung Abu Hanafi an-Nu'man)(6 Ramadhan 1347 H/15 Februari 1929 M);

- At-Tamsiyyatu al-Islamiyyah fii Manaqibi al-Aimmati alArba'ata (Pamapah-keun budak-budak bangsa Islam dina nerangkeun kana Manaqib Imam anu Opat);

- Al-Mufhimaatu Fii Daf'i alKhoyalaati (Tammat waktu Dzuhur dinten Sabtu 20 Ramadhan 1347 H/ 2 Maret 1929 M);

- Tahdziiru al-'Awaam Min Muftariyaati Cahya Islam (Mere inget ka sakabeh jalma awam kudu sieun tina sakabeh cacian bohongna kaum surat kabar Cahaya Islam) (Tammat ieu risalah pukul 7 isuk-isukna poe Rebo
24 bulan Ramadhan 1347 H/06 Maret 1929 M, di Tanah Tinggi Senen Nomor 191 Waltafrodun Batawi);

- Silahul Baasil Fiil Dharbi 'Ala Tazaahiiqul Baathil (Ditulis tammat jam 07 isukisuk poe Rebo, 24 Ramadhan 1347 H/06 Maret 1929 M);

- Al-Adwiyyata asy-Syaafiyatu Fii bayaani Sholaati alHajaati wa al-Istikharaati wa Tafriihi al-Kurbati (Tammat poe Rebo pukul 3 Rabiul Awal tanggal 22 tahun $1348 \quad \mathrm{H} /$ Kampung Kwitang Batavia/ 27 Agustus 1929 M);

- As-Suyuufu ash-Shoorimah Fii ar-Roddi 'Alaa alFatawaa al-Baathilah (Pirang-piran Nash anu saperti pedang-pedang anu seukeut dina nulak kana Fatwa anu salah bathal) (Tammat ngumpulkeun ieu 
Risalah pukul 12 poe Khomis tanggal 28 Rabiul Akhir Tahun 1348 H/3 Oktober 1929 M, Di Kampung Kwitang Batavia Centrum);

- Tahdziiru al-'Awaam Min Muftariyaati Cahya Islam (Mere inget ka sakabeh jalma awam kudu sieun tina sakabeh cacian bohongna kaum surat kabar Cahaya Islam) (Tammat ieu risalah pukul 6 sore poe Salasa 14 bulan Jumadil Awal 1348 H ?/ 17 Oktober 1929 M, di Tanah Tinggi Senen Nomor 191 Waltafrodun Batawi);

- Kitab Maljau ath-Tholibiin Fii Tafsiiri Kalami Robbil 'Alamiin-Juz ka-30 (Panyalindungan SantriSantri dina nafsiran dahuwan Allah Ta'ala)(Tammat di tulis pukul 2 poe Rebo, 15 Hafit 1348 H/15 April 1930 M, di Gang Kampung Bali Kecil Tanah Abang Waltafridun);
- Taju al-Mafaakhir Fii Tarjamati Tafriihu al-Khootir Fii Manakibi as-Sayidi Abdul Qodir (Makutana pirangpirang Kaluhungan dina nerjemahkeun Tafriihul Khootir dina nerangkeun Manakib Sayyid Abdul Qodir)(etakan kadua 12 Rabiul Awal 1349 H/ Kamis, 7 Agustus 1930 M);

- Tadzkiratu ath-Thoolibiin Fii Bayaani Sunniyati at-Talqiin (Memberi inget ka santrisantri dina nerangkeun kana sunnatna nalqinkeun mayyit) (Tammat ieu risalah jam satengah tujuh isuk poe Ahad tanggal 16 Rajab tahun 1349 H/ 7 Desember 1930 M, di Tanah Tinggi Senen No.191 Waltafriidun Batawi);

- Majma'ul Fawaid Fii Tafsiiri Qowa'idil al-'Aqiiidi liljaahili (Kumpulan pirangpirang manfaat dina 
nafsirkeun aturan-aturan Aqidah pikeun jalma bodo) (10 Mei 1931);

- Tauhidul Muslimin wa Aqoidul Mu'minin (Tauhidna jalma Muslim jeung Aqidahna jalma Iman) (Tammat ditulis pukul 10 dinten Jum'at, 4 Maulud 1351 H/8 Juli 1932 M, di Tanah Tinggi Senen Nomor 191 Batavia Karamat);

- Fadhaairu Kasabi alIkhtiyaari Fii az-Zaami Aqwaahu al-Wa'aadhi alGodaari (Segala kelebihannya mencari dan berusaha kehidupan didalam mengekang segala mulutnya tukang ngajaring Kincang (?) yang suka menipu orang)(Tammat jam satengah empat Ashar hari Rebo tanggal 01 Nopember 1933 M/13 Rajab 1353 H, di Tanah Tinggi Senen No.191 Batavia Centrum);
- Jauhaaru al-Bahiyyati Fii Adaabi al-Mar'ati alMutazawwajati (Segala Berlian yang amat indah menerangkan segala adabadabannya istri kepada suaminya)(Tammat jam 12 hari Kamis tanggal 24 Dzulhijjah 1351 H/19 April 1933 M di Tanah Tinggi Senen Nomo 191 Batavia Centrum);

- Ar-Ru'undiyyah Fii Mahwibda'i adhDhawaabith alQonthuriyyah (Sakabeh Hujjah-hujjah anu saperti geledeg buat ngancurkeun sakabeh pabid'ahanpabid'ahan Kitab Dhawabith anu dikarang $\mathrm{ku}$ ajengan Gentur)(Tammat pukul 7 ba'da Magrib malam Kamis tanggal 4 Rabiul Akhir 1352 H/27 Juni 1933 M, di Tanah Tinggi Pasar Senen Batavia Centrum); 
- Du'a Nabiyallah Ibrahim (Tamat pukul 01.00 WIB poe Rebo, 14 Dzulqo'idah 1352 H/28 Februari 1934 M);

- As-Siraaju al-Wahaaj Fii alIsroo wa al-Mi'raaj;

- Bahru al-Madad Fii Tarjamati Ayyuhaa al-Walad (Laut pertulungan dina nerjemahkeun Kitab Ayyuhal Walad karangan Imam Ghozali);

- Duruusu an-Nahwiyah Fii Kaifiyatu Tadriis alJurmiyyah (Pengajaran ilmuilmu Nahwu di dalam menyhatakan pengajaran kitab al-Jurmiyah);

- Sirooju al-Ummati Fii Khoshooishu al-Jum'ah (Damarna Ummat Islam Nerangkeun kana rupa-rupa khusushiyyat Jum'at (Di Tanah Tinggi Senen No.191 Batavia Karamat);
- Fathu al-Muqollatain Fii Bayaani Shikhoti alJum'atain (Membukakan dua biji mata didalam menyatakan syahnya dua pendirian jum'ah);

- Tanbiihu ath-Thulaabati Fii Khutbati al-Jum'ati Bigoiri al-'Arobiyyah (Peringatan bagi yang menuntut ilmu tentang Khutbah Jum'ah dengan bukan Bahasa Arab);

- Nurul Yaqiin Juz ke-2 (Tanah Tinggi Senen Batavia Karamat No.191).

- Maljau ath-Thaalibien fie Tafsieri Kalami Robbil 'aalamien. Juz ka-30. (Panyalindungan Santri dina Nafsiran Dahuwan Allah Ta'ala) (Ditulis selesai pukul 14.00 WIB hari Rabu tanggal 15 Dzulqo'idah 1348 H/16 April 1930 M). Tanah Tinggi Senen Batavia Karamat; 
- Maljau ath-Thaalibien fie Tafsieri Kalami Robbil 'aalamien. (Panyalindungan Santri-Santri dina Nafsiran Kalamna Robbul'Alamiin). Jilid Nommer $1, \quad(9$ Ramadhan 1349 H/28 Januari 1931 M). Tanah Tinggi Senen Waltepreeduun Karamat Batavia. Dicetak di Kantor Cetak sareng Toko Kitab Harun bin Ali Ibrahim Pekojan 3 Batawi;

- Maljau ath-Thaalibien fie Tafsieri Kalami Robbil 'aalamien. (Panyalindungan Santri-Santri dina Nafsiran Kalamna Robbul'Alamiin). Jilid Nommer 2, (10 Syawal 1349 H/28 Februari 1931 M). Tanah Tinggi Senen No.191 Batavia Karamat. Dicetak di Kantor Cetak sareng Toko Kitab Harun bin Ali Ibrahim Pekojan No.177 Batawi;
- Maljau ath-Thaalibien fie Tafsieri Kalami Robbil 'aalamien. (Panyalindungan Santri-Santri dina Nafsiran Kalamna Robbul'Alamiin). Jilid Nommer 3, (9 Hapit 1349 H/28 Maart 1931 M). Tanah Tinggi Senen No.191 Batavia Karamat. Dicetak di Kantor Cetak sareng Toko Kitab Harun bin Ali Ibrahim Pekojan No.177 Batawi;

- Maljau ath-Thaalibien fie Tafsieri Kalami Robbil 'aalamien. (Panyalindungan Santri-Santri dina Nafsiran Kalamna Robbul'Alamiin). Jilid Nommer 4, (10 Dzulhijjah 1349 H/28 April 1931 M). Tanah Tinggi Senen No.191 Batavia Karamat. Dicetak di Kantor Cetak sareng Toko Kitab Harun bin Ali Ibrahim Pekojan No.177 Batawi; 
- Maljau ath-Thaalibien fie Tafsieri Kalami Robbil 'aalamien. (Panyalindungan Santri-Santri dina Nafsiran Kalamna Robbul'Alamiin). Jilid Nommer 5, (10 Muharram 1350 H/28 Mei 1931 M). Tanah Tinggi Senen No.191 Batawi Karamat;

- Maljau ath-Thaalibien fie Tafsieri Kalami Robbil 'aalamien. (Panyalindungan Santri-Santri dina Nafsiran Kalamna Robbul'Alamiin). Jilid Nommer 6, (12 Shafar 1350 H/28 Juni 1931 M). Tanah Tinggi Senen No.191 Batavia Karamat;

- Maljau ath-Thaalibien fie Tafsieri Kalami Robbil 'aalamien. (Panyalindungan Santri-Santri dina Nafsiran Kalamna Robbul'Alamiin). Jilid Nommer 7, (12 Rabbi'ul Awwal 1350 H/28 Juli 1931
M). Tanah Tinggi Senen No.191 Batavia Karamat;

- Maljau ath-Thaalibien fie Tafsieri Kalami Robbil 'aalamien. (Panyalindungan Santri-Santri dina Nafsiran Kalamna Robbul'Alamiin). Jilid Nommer 8, (14 Rabbi'ul Tsani $1350 \mathrm{H} / 28$ Agustus 1931 M). Tanah Tinggi Senen No.191 Batawi Karamat;

- Maljau ath-Thaalibien fie Tafsieri Kalami Robbil 'aalamien. (Panyalindungan Santri-Santri dina Nafsiran Kalamna Robbul'Alamiin). Jilid Nommer 9, (22 Sya'ban 1350 H/1 Januari 1932 M). di Tanah Tinggi Senen Batawi Karamat;

- Maljau ath-Thaalibien fie Tafsieri Kalami Robbil 'aalamien. (Panyalindungan Santri-Santri dina Nafsiran Kalamna Robbul'Alamiin). 
Jilid Nommer 10 Tahun ka II, (Juni 1932). di Tanah Tinggi Senen No.191 Batavia Karamat. Dicetak dikantor Cetak Al-Ittihad Tanah Tinggi Poncol No.65 Batavia;

- Al-Isyarah fi al-Farqi Baena ash-Shodaqoh wa alDhiyaafah (Nuduhkeun kana bedana antara shodaqoh reujeung Dliyafah). Dicetak dikantor Cetak Al-Ittihad Poncol Tanah Tinggi Senen Batavia Centrum;

- Maljau ath-Thaalibien fie Tafsieri Kalami Robbil 'aalamien. (Panyalindungan Santri-Santri dina Nafsiran Kalamna Robbul'Alamiin). Jilid Nommer 11 Tahun ka II, (Agustus 1932). Tanah Tinggi Senen No.191 Batavia Karamat. Dicetak dikantor Cetak Al-Ittihad Tanah Tinggi Poncol No.65 Batavia;
- Maljau ath-Thaalibien fie Tafsieri Kalami Robbil 'aalamien. (Panyalindungan Santri-Santri dina Nafsiran Kalamna Robbul'Alamiin). Jilid Nommer 12 Tahun ka II, (September1932). Tanah Tinggi Senen No.191 Batawi Karamat. Dicetak dikantor Cetak Al-Ittihad Tanah Tinggi Poncol No.65 Batavia;

- Maljau ath-Thaalibien fie Tafsieri Kalami Robbil 'aalamien. (Panyalindungan Santri-Santri dina Nafsiran Kalamna Robbul'Alamiin). Jilid Nommer 13, Tahun ka III, (Mei-Juni 1933). di Tanah Tinggi Senen No.191 Batavia Karamat. Dicetak dikantor Al-Ittihad;

- Maljau ath-Thaalibien fie Tafsieri Kalami Robbil 'aalamien. (Panyalindungan Santri-Santri dina Nafsiran 
Kalamna Robbul'Alamiin). Jilid Nommer 14 Tahun ka III, (Januari-Februari 1934). Tanah Tinggi Senen No. 191 Batavia Karamat. Dicetak dikantor Cetak sareng Toko Kitab Al-Ittihad;

- Maljau ath-Thaalibien fie Tafsieri Kalami Robbil 'aalamien. (Panyalindungan Santri-Santri dina Nafsiran Kalamna Robbul'Alamiin). Jilid Nommer 15 Tahun ka III, (Mei-Juni 1934). Tanah Tinggi Senen No.191 Batavia Centrum. Dicetak dikantor Cetak sareng Toko Kitab AlIttihad;

- Maljau ath-Thaalibien fie Tafsieri Kalami Robbil 'aalamien. (Panyalindungan Santri-Santri dina Nafsiran Kalamna Robbul'Alamiin). Jilid Nommer 16 Tahun ka III, (October-Nopember 1933). Tanah Tinggi Senen 191 Batavia Centrum;
Dicetak dikantor Cetak AlIttihad Tanah Tinggi No.26 Batavia Centrum;

- Maljau ath-Thaalibien fie Tafsieri Kalami Robbil 'aalamien. (Panyalindungan Santri-Santri dina Nafsiran Kalamna Robbul'Alamiin). Jilid Nommer 17, (). di Tanah Tinggi Senen 191 Batavia Centrum;

- Maljau ath-Thaalibien fie Tafsieri Kalami Robbil 'aalamien. (Panyalindungan Santri-Santri dina Nafsiran Kalamna Robbul'Alamiin). Jilid Nommer 18, (). di Tanah Tinggi Senen 191 Batavia Karamat;

- Maljau ath-Thaalibien fie Tafsieri Kalami Robbil 'aalamien. (Panyalindungan Santri-Santri dina Nafsiran Kalamna Robbul'Alamiin). Jilid Nommer 19, (). di Tanah 
Tinggi Senen 191 Batavia Karamat.

5. Tahun 1934-1939 sewaktu dipindahkan ke Sukabumi dengan status tahanan Kota di De Vogel Weg/Gunungpuyuh, ia menulis beberapa kitab,diantaranya :

- Maljau ath-Thaalibien fie Tafsieri Kalami Robbil 'aalamien. (Panyalindungan Santri-Santri dina Nafsiran Kalamna Robbul'Alamiin). Jilid Nommer 20, (). De Vogelweg Soekaboemi;

- Maljau ath-Thaalibien fie Tafsieri Kalami Robbil 'aalamien. (Panyalindungan Santri-Santri dina Nafsiran Kalamna Robbul'Alamiin). Jilid Nommer 21, (Februari tahoen 1936). De Vogelweg Soekaboemi;

- Maljau ath-Thaalibien fie Tafsieri Kalami Robbil 'aalamien. (Panyalindungan
Santri-Santri dina Nafsiran Kalamna Robbul'Alamiin). Jilid Nommer 22, (). De Vogelweg 100 Soekaboemi;

- Maljau ath-Thaalibien fie Tafsieri Kalami Robbil 'aalamien. (Panyalindungan Santri-Santri dina Nafsiran Kalamna Robbul'Alamiin). Jilid Nommer 23, (Maanblad No.23 Juli 1936). De Vogelweg 100 Soekaboemi;

- Maljau ath-Thaalibien fie Tafsieri Kalami Robbil 'aalamien. (Panyalindungan Santri-Santri dina Nafsiran Kalamna Robbul'Alamiin). Jilid Nommer 24, (Maanblad No.24, September tahoen 1936). De Vogelweg 100 Soekaboemi;

- Tamsiyyatoel-Moeslimien Fie Tafsieri Kalami Robbil'Alamien (Menindakkan sekalian orang Islam, didalam menafsierkan firman 
Toehan seroe sekalian 'alam), Nummer 1, Tahun ka I (01 Oktober 1934), Typ, MASDOEKI, Tarikolot 3, Soekaboemi;

- Tamsiyyatoel-Moeslimien

Fie Tafsieri Kalami Robbil'Alamien (Menindakkan sekalian orang Islam, didalam menafsierkan firman Toehan seroe sekalian 'alam), Nummer 2, Tahun ka I (November 1934), Druk. Al-Ittihad Soekaboemi;

- Tamsiyyatoel-Moeslimien

Fie Tafsieri Kalami Robbil'Alamien (Menindakkan sekalian orang Islam, didalam menafsierkan firman Toehan seroe sekalian 'alam), Nummer 3, Tahun ka I (Desember 1934), Druk. AlIttihad Soekaboemi;

- Tamsiyyatoel-Moeslimien Fie Tafsieri Kalami Robbil'Alamien (Menindakkan sekalian orang Islam, didalam menafsierkan firman Toehan seroe sekalian 'alam), Nummer 4, Tahun ka II (Januari 1935), Druk. AlIttihad Soekaboemi;

- Tamsiyyatoel-Moeslimien Fie Tafsieri Kalami Robbil'Alamien (Menindakkan sekalian orang Islam, didalam menafsierkan firman Toehan seroe sekalian 'alam), Nummer 5, Tahun ka II (Februari 1935), Druk. AlIttihad Soekaboemi;

- Tamsiyyatoel-Moeslimien Fie Tafsieri Kalami Robbil'Alamien (Menindakkan sekalian orang Islam, didalam menafsierkan firman Toehan seroe sekalian 'alam), Nummer 6, Tahun ka II (Maart 1935), Druk. AlIttihad Soekaboemi;

- Tamsiyyatoel-Moeslimien Fie Tafsieri Kalami Robbil- 
'Alamien (Menindakkan sekalian orang Islam, didalam menafsierkan firman Toehan seroe sekalian 'alam), Nummer 7, Tahun ka II (April 1935), Druk. AlIttihad Soekaboemi;

- Tamsiyyatoel-Moeslimien Fie Tafsieri Kalami Robbil'Alamien (Menindakkan sekalian orang Islam, didalam menafsierkan firman Toehan seroe sekalian 'alam), Nummer 8, Tahun ka II (Mei 1935);

- Tamsiyyatoel-Moeslimien Fie Tafsieri Kalami Robbil'Alamien (Menindakkan sekalian orang Islam, didalam menafsierkan firman Toehan seroe sekalian 'alam), Nummer 9, Tahun ka II (Juni 1935), Druk. AlIttihad Soekaboemi;

- Tamsiyyatoel-Moeslimien Fie Tafsieri Kalami Robbil-
'Alamien (Menindakkan sekalian orang Islam, didalam menafsierkan firman Toehan seroe sekalian 'alam), Nummer 10, Tahun ka II (Juli 1935), Druk. AlIttihad Soekaboemi;

- Tamsiyyatoel-Moeslimien Fie Tafsieri Kalami Robbil'Alamien (Menindakkan sekalian orang Islam, didalam menafsierkan firman Toehan seroe sekalian 'alam), Nommer 11, Tahun ka II (Augustus 1935), Druk. Al-Ittihad Soekaboemi;

- Tamsiyyatoel-Moeslimien Fie Tafsieri Kalami Robbil'Alamien (Menindakkan sekalian orang Islam, didalam menafsierkan firman Toehan seroe sekalian 'alam), Nommer 12, Tahun ka II (September 1935), Druk. Al-Ittihad Soekaboemi; 
- Tamsiyyatoel-Moeslimien

Fie Tafsieri Kalami Robbil'Alamien (Menindakkan sekalian orang Islam, didalam menafsierkan firman Toehan seroe sekalian 'alam), Nommer 13, Tahun ka II (October 1935), Druk.

\section{Al-Ittihad Si.;}

- Tamsiyyatoel-Moeslimien

Fie Tafsieri Kalami Robbil'Alamien (Menindakkan sekalian orang Islam, didalam menafsierkan firman Toehan seroe sekalian 'alam), Nommer 14, Tahun ka II (November 1935), Druk. Al-Ittihad Si.;

- Tamsiyyatoel-Moeslimien Fie Tafsieri Kalami Robbil'Alamien (Menindakkan sekalian orang Islam, didalam menafsierkan firman Toehan seroe sekalian 'alam), Nommer 15, Tahun ka II (December 1935), Druk. Al-Ittihad Si.;

- Tamsiyyatoel-Moeslimien Fie Tafsieri Kalami Robbil'Alamien (Menindakkan sekalian orang Islam, didalam menafsierkan firman Toehan seroe sekalian 'alam), Nommer 16, Tahun ka III (Januari 1936), Druk. Al-Ittihad Si.;

- Tamsiyyatoel-Moeslimien Fie Tafsieri Kalami Robbil'Alamien (Menindakkan sekalian orang Islam, didalam menafsierkan firman Toehan seroe sekalian 'alam), Nommer 17, Tahun ka III (Februari 1936), Druk. Al-Ittihad Si.;

- Tamsiyyatoel-Moeslimien Fie Tafsieri Kalami Robbil'Alamien (Menindakkan sekalian orang Islam, didalam menafsierkan firman Toehan seroe sekalian 
'alam), Nommer 18, Tahun ka III (Maart 1936), Druk. Al-Ittihad Si.;

- Tamsiyyatoel-Moeslimien

Fie Tafsieri Kalami Robbil'Alamien (Menindakkan sekalian orang Islam, didalam menafsierkan firman Toehan seroe sekalian 'alam), Nommer 19, Tahun ka III (April 1936), Druk. AlIttihad Si.;

- Tamsiyyatoel-Moeslimien Fie Tafsieri Kalami Robbil'Alamien (Menindakkan sekalian orang Islam, didalam menafsierkan firman Toehan seroe sekalian 'alam), Nommer 20, Tahun ka III (Mei 1936), Druk. AlIttihad Si.;

- Tamsiyyatoel-Moeslimien

Fie Tafsieri Kalami Robbil'Alamien (Menindakkan sekalian orang Islam, didalam menafsierkan firman
Toehan seroe sekalian 'alam), Nommer 21, Tahun ka III (Juni 1936), Druk. AlIttihad Si.;

- Tamsiyyatoel-Moeslimien Fie Tafsieri Kalami Robbil'Alamien (Menindakkan sekalian orang Islam, didalam menafsierkan firman Toehan seroe sekalian 'alam), Nommer 22, Tahun ka III (Juli 1936), Druk. AlIttihad Si.;

- Tamsiyyatoel-Moeslimien Fie Tafsieri Kalami Robbil'Alamien (Menindakkan sekalian orang Islam, didalam menafsierkan firman Toehan seroe sekalian 'alam), Nommer 23, Tahun ka III (Augustus 1936), Druk. Al-Ittihad Si.;

- Tamsiyyatoel-Moeslimien Fie Tafsieri Kalami Robbil'Alamien (Menindakkan sekalian orang Islam, 
didalam menafsierkan firman Toehan seroe sekalian 'alam), Nommer 24, Tahun ka III (September 1936), Druk. Al-Ittihad Si.;

- Tamsiyyatoel-Moeslimien Fie Tafsieri Kalami Robbil'Alamien (Menindakkan sekalian orang Islam, didalam menafsierkan firman Toehan seroe sekalian 'alam), Nommer 25, Tahun ka III (October 1936), Druk. Al-Ittihad Si.;

- Tamsiyyatoel-Moeslimien

Fie Tafsieri Kalami Robbil'Alamien (Menindakkan sekalian orang Islam, didalam menafsierkan firman Toehan seroe sekalian 'alam), Nommer 26, Tahun ka III (November 1936), Druk. Al-Ittihad Si.;

- Tamsiyyatoel-Moeslimien Fie Tafsieri Kalami Robbil'Alamien (Menindakkan sekalian orang Islam, didalam menafsierkan firman Toehan seroe sekalian 'alam), Nommer 27, Tahun ka III (December1936), Druk. Al-Ittihad Si.;

- Tamsiyyatoel-Moeslimien Fie Tafsieri Kalami Robbil'Alamien (Menindakkan sekalian orang Islam, didalam menafsierkan firman Toehan seroe sekalian 'alam), Nommer 28, Tahun ka IV (3 Januari 1937), Druk. Al-Ittihad Si.;

- Tamsiyyatoel-Moeslimien Fie Tafsieri Kalami Robbil'Alamien (Menindakkan sekalian orang Islam, didalam menafsierkan firman Toehan seroe sekalian 'alam), Nommer 29, Tahun ka IV (20 Januari 1937), Druk. Al-Ittihad Si.;

- Tamsiyyatoel-Moeslimien Fie Tafsieri Kalami Robbil- 


\begin{abstract}
'Alamien (Menindakkan sekalian orang Islam, didalam menafsierkan firman
\end{abstract} Toehan seroe sekalian 'alam), Nommer 30, Tahun ka IV (5 Februari 1937), Druk. Al-Ittihad Si.;

- Tamsiyyatoel-Moeslimien Fie Tafsieri Kalami Robbil'Alamien (Menindakkan sekalian orang Islam, didalam menafsierkan firman Toehan seroe sekalian 'alam), Nommer 31, Tahun ka IV (20 Februari 1937), Typ. A.I.I.;

- Tamsiyyatoel-Moeslimien Fie Tafsieri Kalami Robbil'Alamien (Menindakkan sekalian orang Islam, didalam menafsierkan firman Toehan seroe sekalian 'alam), Nommer 32, Tahun ka IV (5 Maart 1937),Typ. A.I.I.;
- Tamsiyyatoel-Moeslimien Fie Tafsieri Kalami Robbil'Alamien (Menindakkan sekalian orang Islam, didalam menafsierkan firman Toehan seroe sekalian 'alam), Nommer 33, Tahun ka IV (20 Maart 1937), Typ. A.I.I.;

- Tamsiyyatoel-Moeslimien Fie Tafsieri Kalami Robbil'Alamien (Menindakkan sekalian orang Islam, didalam menafsierkan firman Toehan seroe sekalian 'alam), Nommer 34, Tahun ka IV (5 April 1937), Typ. A.I.I.;

- Tamsiyyatoel-Moeslimien Fie Tafsieri Kalami Robbil'Alamien (Menindakkan sekalian orang Islam, didalam menafsierkan firman Toehan seroe sekalian 'alam), Nommer 35, Tahun 
ka IV (20 April 1937), Typ.

$$
\text { A.I.I.; }
$$

- Tamsiyyatoel-Moeslimien

Fie Tafsieri Kalami Robbil'Alamien (Menindakkan sekalian orang Islam, didalam menafsierkan firman Toehan seroe sekalian 'alam), Nommer 36, Tahun ka IV (5 Mei 1937), Typ.

\section{A.I.I.;}

- Tamsiyyatoel-Moeslimien

Fie Tafsieri Kalami Robbil'Alamien (Menindakkan sekalian orang Islam, didalam menafsierkan firman Toehan seroe sekalian 'alam), Nommer 37, Tahun ka IV (20 Mei 1937), Typ.

\section{A.I.I.;}

- Tamsiyyatoel-Moeslimien

Fie Tafsieri Kalami Robbil'Alamien (Menindakkan sekalian orang Islam, didalam menafsierkan firman Toehan seroe sekalian 'alam), Nommer 38, Tahun ka IV (5 Juni 1937), Typ. A.I.I.;

- Tamsiyyatoel-Moeslimien Fie Tafsieri Kalami Robbil'Alamien (Menindakkan sekalian orang Islam, didalam menafsierkan firman Toehan seroe sekalian 'alam), Nommer 39, Tahun ka IV (20 Juni 1937), Typ. A.I.I.;

- Tamsiyyatoel-Moeslimien Fie Tafsieri Kalami Robbil'Alamien (Menindakkan sekalian orang Islam, didalam menafsierkan firman Toehan seroe sekalian 'alam), Nommer 40, Tahun ka IV (5 Juli 1937), Typ. A.I.I.;

- Tamsiyyatoel-Moeslimien Fie Tafsieri Kalami Robbil'Alamien (Menindakkan sekalian orang Islam, didalam menafsierkan firman 
Toehan seroe sekalian 'alam), Nommer 41, Tahun ka IV (20 Juli 1937), Typ.

\section{A.I.I.;}

- Tamsiyyatoel-Moeslimien

Fie Tafsieri Kalami Robbil'Alamien (Menindakkan sekalian orang Islam, didalam menafsierkan firman Toehan seroe sekalian 'alam), Nommer 42, Tahun ka IV (5 Augustus 1937), Typ. A.I.I.;

- Tamsiyyatoel-Moeslimien Fie Tafsieri Kalami Robbil'Alamien (Menindakkan sekalian orang Islam, didalam menafsierkan firman Toehan seroe sekalian 'alam), Nommer 43, Tahun ka IV (20 Augustus 1937), Typ. A.I.I.;

- Tamsiyyatoel-Moeslimien Fie Tafsieri Kalami Robbil'Alamien (Menindakkan sekalian orang Islam, didalam menafsierkan firman Toehan seroe sekalian 'alam), Nommer 44, Tahun ka IV (5 September 1937), Typ. Masdoeki.;

- Tamsiyyatoel-Moeslimien Fie Tafsieri Kalami Robbil'Alamien (Menindakkan sekalian orang Islam, didalam menafsierkan firman Toehan seroe sekalian 'alam), Nommer 45, Tahun ka IV (20 September 1937), Typ. Masdoeki.;

- Tamsiyyatoel-Moeslimien Fie Tafsieri Kalami Robbil'Alamien (Menindakkan sekalian orang Islam, didalam menafsierkan firman Toehan seroe sekalian 'alam), Nommer 46, Tahun ka IV (5 October1937), Typ. Masdoeki.;

- Tamsiyyatoel-Moeslimien Fie Tafsieri Kalami Robbil'Alamien (Menindakkan 
sekalian orang Islam, didalam menafsierkan firman Toehan seroe sekalian 'alam), Nommer 47, Tahun ka IV (20 October 1937), Typ. Masdoeki.;

- Tamsiyyatoel-Moeslimien Fie Tafsieri Kalami Robbil'Alamien (Menindakkan sekalian orang Islam, didalam menafsierkan firman Toehan seroe sekalian 'alam), Nommer 48, Tahun ka IV (5 November 1937), Typ. Masdoeki.;

- Tamsiyyatoel-Moeslimien

Fie Tafsieri Kalami Robbil'Alamien (Menindakkan sekalian orang Islam, didalam menafsierkan firman Toehan seroe sekalian 'alam), Nommer 49, Tahun ka IV (20 November 1937), Typ. Masdoeki.;

- Tamsiyyatoel-Moeslimien Fie Tafsieri Kalami Robbil-
'Alamien (Menindakkan sekalian orang Islam, didalam menafsierkan firman Toehan seroe sekalian 'alam), Nommer 50, Tahun ka VI (20 Maart 1939), Typ. Masdoeki.;

- Tamsiyyatoel-Moeslimien Fie Tafsieri Kalami Robbil'Alamien (Menindakkan sekalian orang Islam, didalam menafsierkan firman Toehan seroe sekalian 'alam), Nommer 51, Tahun ka VI (April 1939), Druk. AlIttihad Si.;

- Tamsiyyatoel-Moeslimien Fie Tafsieri Kalami Robbil'Alamien (Menindakkan sekalian orang Islam, didalam menafsierkan firman Toehan seroe sekalian 'alam), Nommer 52, Tahun ka VI (Mei 1939), Typ. Masdoeki.; 
- Tamsiyyatoel-Moeslimien

Fie Tafsieri Kalami Robbil'Alamien (Menindakkan sekalian orang Islam, didalam menafsierkan firman Toehan seroe sekalian 'alam), Nommer 53, Tahun ka III (Juni1939), Typ. Masdoeki.;

- Raudhatul Irfan fie Ma'rifatul Qur'an (Kebon rupa-rupa Ilmu jeung Nganyahokeun Maksudna Qur'an), Juz 1. Tanpa Tahun. Sukabumi : Yayasan Asrama Pesantren Gunungpuyuh Sukabumi;

- Raudhatul Irfan fie Ma'rifatul Qur'an (Kebon rupa-rupa Ilmu jeung Nganyahokeun Maksudna Qur'an), Juz 2. Tanpa Tahun. Sukabumi : Kuta Mas Sukabumi;

- Raudhatul Irfan fie Ma'rifatul Qur'an (Kebon rupa-rupa Ilmu jeung Nganyahokeun Maksudna Qur'an), Juz 3. Tanpa Tahun. Sukabumi : Yayasan Asrama Pesantren Gunungpuyuh Sukabumi;

- Raudhatul Irfan fie Ma'rifatul Qur'an (Kebon rupa-rupa Ilmu jeung Nganyahokeun Maksudna Qur'an), Juz 4. Tanpa Tahun. Sukabumi : Kuta Mas Sukabumi;

- Raudhatul Irfan fie Ma'rifatul Qur'an (Kebon rupa-rupa Ilmu jeung Nganyahokeun Maksudna Qur'an), Juz 5. Buttenzorg : Ang Tjio Drukkerij;

- Raudhatul Irfan fie Ma'rifatul Qur'an (Kebon rupa-rupa Ilmu jeung Nganyahokeun Maksudna Qur'an), Juz 6. Buttenzorg : Ang Tjio Drukkerij; 
- Raudhatul Irfan fie Ma'rifatul Qur'an (Kebon rupa-rupa Ilmu jeung Nganyahokeun Maksudna Qur'an), Juz 7. Tanpa Tahun. Sukabumi : Yayasan Asrama Pesantren Gunungpuyuh Sukabumi;

- Raudhatul Irfan fie Ma'rifatul Qur'an (Kebon rupa-rupa Ilmu jeung Nganyahokeun Maksudna Qur'an), Juz 8. Tanpa Tahun. Sukabumi : Yayasan Asrama Pesantren Gunungpuyuh Sukabumi;

- Raudhatul Irfan fie Ma'rifatul Qur'an (Kebon rupa-rupa Ilmu jeung Nganyahokeun Maksudna Qur'an). Juz 9. Tanpa Tahun. Sukabumi: Yayasan Asrama Pesantren Gunungpuyuh Sukabumi;

- Raudhatul Irfan fie Ma'rifatul Qur'an (Kebon rupa-rupa Ilmu jeung Nganyahokeun Maksudna Qur'an), Juz 10. Tanpa Tahun. Sukabumi : Yayasan Asrama Pesantren Gunungpuyuh Sukabumi;

- Raudhatul Irfan fie Ma'rifatul Qur'an (Kebon rupa-rupa Ilmu jeung Nganyahokeun Maksudna Qur'an), Juz 11. Tanpa Tahun. Sukabumi : Yayasan Asrama Pesantren Gunungpuyuh Sukabumi;

- Raudhatul Irfan fie Ma'rifatul Qur'an (Kebon rupa-rupa Ilmu jeung Nganyahokeun Maksudna Qur'an), Juz 12. Tanpa Tahun. Sukabumi : Yayasan Asrama Pesantren

Gunungpuyuh Sukabumi;

- Raudhatul Irfan fie Ma'rifatul Qur'an (Kebon rupa-rupa Ilmu jeung Nganyahokeun Maksudna 
Qur'an), Juz 13. Tanpa

Tahun. Sukabumi : Typ. Insulinde Si.;

- Raudhatul Irfan fie Ma'rifatul Qur'an (Kebon rupa-rupa Ilmu jeung Nganyahokeun Maksudna Qur'an), Juz 14. Tanpa Tahun. Sukabumi : Yayasan Asrama Pesantren Gunungpuyuh Sukabumi;

- Raudhatul Irfan fie Ma'rifatul Qur'an (Kebon rupa-rupa Ilmu jeung Nganyahokeun Maksudna Qur'an), Juz 15. Tanpa Tahun. Sukabumi : Yayasan Asrama Pesantren

Gunungpuyuh Sukabumi;

- Raudhatul Irfan fie Ma'rifatul Qur'an (Kebon rupa-rupa Ilmu jeung Nganyahokeun Maksudna Qur'an), Juz 16. Tanpa Tahun. Sukabumi : Yayasan
Asrama

Pesantren

Gunungpuyuh Sukabumi;

- Raudhatul Irfan fie Ma'rifatul Qur'an (Kebon rupa-rupa Ilmu jeung Nganyahokeun Maksudna Qur'an), Juz 17. Tanpa Tahun. Cianjur : Percetakan Sansilan al-Ikhlas Cianjur;

- Raudhatul Irfan fie Ma'rifatul Qur'an (Kebon rupa-rupa Ilmu jeung Nganyahokeun Maksudna Qur'an), Juz 18. Tanpa Tahun. Sukabumi : Yayasan Asrama Pesantren Gunungpuyuh Sukabumi;

- Raudhatul Irfan fie Ma'rifatul Qur'an, Juz 30. Tanpa Tahun. Sukabumi: Yayasan Asrama Pesantren Gunungpuyuh Sukabumi;

- Raudhatul Irfan fie Ma'rifatul Qur'an, Juz 1-15. Tanpa Tahun. Sukabumi: 
Yayasan Asrama Pesantren

Gunungpuyuh Sukabumi;

- Raudhatul Irfan fie Ma'rifatul Qur'an, Juz 1630. Tanpa Tahun. Sukabumi: Yayasan Asrama Pesantren Gunungpuyuh Sukabumi;

- Tamsyiyatul Daraari (Ieu kitab nerangkeun kana risalah Ibrahim Bajuri);

- Mindharatul Islam Wal Iman Fii Bayani Bid'atun Tadzkiratul Ikhwan (Kehker Islam jeung Iman dina Nerangkeun Pabid'ahanpabid'ahan jeung kasasarankasasaran Kitab Tadzkiratul Ikhwan) (Tammat satengah lima Ashar poe Jum'ah 16 Ramadhan $1354 \quad H / 13$ Desember 1935);

- Miftahu al-Ginaa Mina alQohthi wa al-'Anaa (Kunci pembuka kabeung-haran tina pahilara jeung kapayahan)(1935);
- Mukhtaru ash-Shalawaat (Shalawat pilihan);

- Tas-hilu al-Marajii Fii Tarjamati Maulidi anNabiyyi al-Barzanjii;

- Iiqoodzu al-Himam Fii Ta'liiqi al-Hikam (Ngageuingkeun Himahhimah jeung sumanget dina ngagantungkeun ma'nama'na kitab Hikam);

- Siraaju al-Adzkiyaai Fii Tarjamati al-Azkiyaai (Damarna kabagjaan buwat jalma-jalma anu caralakan dina narjamahkeun Kitab Azkiya);

- Al-Mathlabu al-Asnaa Fii alAsmai al-Husna (Pangarahan anu leuwih alus dina nerangkeun Asmau alHusna);

- Tafriihu Shuduuri alMu'miniina Fii Maulidi Sayyidi al-Mursaliin (Ngabungah-keun Hatena 
Jalma-jalma Mu'min dina nerangkeun Karamatkaramat jeung Irhas-Irhas jeung Mu'jijat-Mu'jijat nabi Muhammad SAW ti memeh dipedalkeun jeung cariosancariosan di pedalkeunnana)(Tammat pukul 6 isuk por Rebo 12 Shafar 1357 H/13 Aprl 1938 M);

- Mathooli'u al-Anwaari Fii Fadhooili al-Istighfar (Tempat Terbitnya segala cahya didalam menyatakan beberapa keutamaan Istighfar);

- Mandlomatu ar-Rijaal Li Sayyidii 'Alii Zaenal 'Abidiin;

- Al-Muthahhiraat Mina alKaafiraat (Katerangankaterangan anu ngabersihkeun tina sagala anu matak kufur) (Di De Vogelweg No. 100 Sukabumi)
- At-Tamsiyyatu al-Islamiyyah Fii Manakibi al-Aimmati alArba'ah (Pamapah-keun budak-budak bangsa Islam nerangkeun kana manakibmanakib Imam anu opat);

- Mishbahu al-Falaah Fii Wirdi al-Masaai wa ashShobaahi;

- Hidaayatu ash-Shomad Fii Matnu al-Zubad (Pituduh Allah anu dimaksud kalawan sagala hajat dina nerangkeun Matan Zubad);

- At-Tanbiihu al-Maahir Fii alMukhoolith wa al-Mujawwir (Peringatan anu mahir dina nurangkeun perkara mukholit jeung mujawir);

- Al-Aqwaalu al-Mufiidah Fii Umuuri al-Munhimah (Pirang-pirang Qaul anu mere faidah dina nerangkeun pirang-pirang perkara anu ka sangka ku jalma awam eta 
sunnah padahal henteu sunnah);

- Al-'Uhuud Fii al-Huduud (Rupa-rupa perjanjian dina pirang-pirang patokan Islam);

- Tahdziiru al-Afkaar Mina al_Igtiroor Bidlolaalati waftiraayati Tashfiyyati alAfkaar (Menakut-nakuti sekalian perkaranya Ummat Islam, dari pada tertipu dengan segala kesesatan dan perbaikannya bohongnya Kitab Tashfiyatu al-Afkaar);

- Tasyqiiqu al-Auhaam Fii arRad'i 'ani Thaghaam (Suatu pembelah segala sangkaan yang salah didalam menolak orang-orang tukang menyesatkan kepada orangorang bodoh);

- Tauhidoel - Moeslimien Wa 'Aqoidoel - Moe'mimnien (Tammat hari Senen tanggal 27 Radjab 1353 H/5 Nov
1934 M, di De Vogelweg Roemah No. 100 Soekaboemi);

- Miftahu al-Jannah Fii Bayaani Ahli as-Sunnah wa al-Jamaa'ah (Kunci pembuka Syurga dina nerangkeun golongan Ahli Sunnah Wal Jama'ah (Gunungpuyuh Sukabumi);

- Al-Isyarah fil Farqi Baenas Shodaqoh wal Dhiayafah (Nuduhkeun kana bedana antara Shodaqoh reujeung Diafah dina Syara') Nomor 30-31 Maanblak JanuariFebruari 1934 Tahun ka-3, Dicitak dikantor Citak AlIttihad Grogol Tanah Tinggi Senen 191 Batavia Centrum.

6. Tahun 1939-1950, sewaktu ia sudah terbebas dari status tahanan kota, ia menulis beberapa kitab, diantaranya :

- Al-Kalimaatu al_mubayyinah Fii Qosiidatu 
Ibnu Hujjah (Kalimahkalimat anu nerangkeun dina ma'nana qosidah Ibnu Hujjah)(Tammat ditulis jam 3 Dzuhur, poe salasa 3 Sya'ab 1360 H/26 Agustus 1941 M);

- As-Silaahu al-Maahiyyah Lithurooqi al-Firaqi alMubtadi'ah (Pekakas anu nganjurkeun kana thoriqohthoriqoh firqoh tukang bid'ah) (Tammat jam satengah salapan Nippon Dhuha poe Jum'ah, 13 Jumadil Awwal $1361 \mathrm{H} / 29$ Mei 2602 Nippon atau 1942 M di Gunungpuyuh Sukabumi).

Kitab-kitab diatas merupakan buah karya K.H. Ahmad Sanusi yang mulai terkumpul untuk bahan Museum K.H. Ahmad Sanusi yang tidak lama lagi akan dibangun di Terminal Type A K.H. Ahmad Sanusi di Kota Sukabumi. Mudahmudahan Kitab lainnya karya K.H. Ahmad Sanusi dapat terkumpul secepatnya sehingga buah karya K.H. Ahmad Sanusi yang jumlahnya ratusan tersebut dapat terlestarikan untuk bahan pelajaran dan kajian bagi generasi sekarang dan masa yang akan datang.

\section{KESIMPULAN}

K.H. Ahmad Sanusi termasuk seorang reformis muslim yang ide-idenya sangat dipengaruhi oleh reformis Muslim terkenal saat itu di Timur Tengah seperti Jamaluddin Al-Afghani, Muhammad Abduh, Syeikh Sayid Ridha, dll. K.H. Ahmad Sanusi, semenjak dari tahun 1914 sampai dengan tahun 1950, adalah seorang penulis nusantara yang produktif. Karya tulis yang ia buat meliputi berbagai disiplin keilmuan diantaranya Ilmu Tauhid, Ilmu Tafsir, Ilmu Qur'an, Ilmu Fiqih, Ilmu Tasawwuf, Ilmu Nahu dan Sharaf, dan ilmu-ilmu lainnya yang mencakup 12 fan keilmuan.

Karyanya saat ini cukup sulit untuk ditemukan karena selain 
sudah tidak ada pencetakan ulang terhadap karya-karya tersebut juga karena sawaktu masa penjajahan Kolonial Belanda karya K.H. Ahmad Sanusi relatif dilarang beredar oleh pemerintah kolonial Belanda baik langsung maupun tidak langsung, karena dianggap tulisannya akan membahayakan terhadap kewibawaan pemerintahan Kolonial Belanda beserta kroni-kroninya, sehingga siapapun yang memiliki karya K.H. Ahmad Sanusi akan diambil atau dirampas baik secara halus maupun secara kasar oleh polisi Belanda atau oleh pejabat pemerintah lokal sebagai kaki tangan dari Pemerintah Kolonial Belanda.

Semoga dengan tersampaikannya sebagian karyakarya K.H. Ahmad Sanusi dalam tulisan ini, akan menambah khasanah keilmuan pada khalayak ramai bahwa di Nusantara masih terdapat penulis produktif pada jamannya yang bisa menjadi motivator bagi generasi berikutnya untuk gemar menulis dan berkarya dalam menyebarkan dan mengembangkan ilmu ke-Islaman kepada ummat manusia.

\section{DAFTAR PUSTAKA}

Iskandar, M. (2001). Para Pengemban Amanah: Pergulatan Pemikiran Kiai dan Ulama di Jawa Barat 1900-1950. Jogyakarta: Mata Bangsa.

Matin, U. A. (2009). K.H. Ahmad Sanusi (1888-1950): His Religio-Intellectual Discourse, and His Work Collection. Dalam Lektur Keagamaan. Jakarta: Puslitbang Lektur Keagamaan Badan Litbangdan Diklat Departemen Agama RI, 7 (1).

Mawardi, Asep Mukhtar. (2011). Haji Ahmad Sanusi dan Kiprahnya dalam Pergolakan Pemikiran KeIslaman dan Pergerakkan Kebangsaan di Sukabumi 1888 - 1950. Tesis Magister Ilmu Sejarah pada Program Pasca Sarjana Universitas Dipenogoro. 
Sanusi, Ahmad. (1930). Maljau ath-Thalibiin Fii Tafsiiri Kalami Robbi al'Alamiin, Juz 30. Batavia: Kantor Percetakan Ahli Sunnah Wal Jama'ah Harun bin Ali Ibrahim Pekojan Batavia.

. (1931-1932). Maljau ath-Thalibiin Fii Tafsiiri Kalami Robbi al- 'Alamiin Jilid 1 - 10. Toko Kitab Harun bin Ali Pakojan Batavia Centrum dan Al-Ittihad Tanah Tinggi Poncol.

., (t.t). ar-Rud'iyyah fii Majwibda'i adh-Dhawaabit alQonthuuriyyah. Tanah Tinggi Batavia: Kantor Cetak dan Toko Kitab alIttihad.

. (1932-1936). Maljau ath-Thalibiin Fii Tafsiiri Kalami Robbi al-'Alamiin Jilid 11-24. Al-Ittihad Tanah Tinggi Poncol Batavia Karamat dan Al-Ittihad Sukabumi.

. (1934). Tamsiyatul Muslimin Fii Tafsiri Kalami Robbil 'Alamiin Jilid 1. Druk Masduki, Sukabumi.

. (1934 - 1937). Tamsiyatul Muslimin Fii Tafsiri Kalami Robbil 'Alamiin Jilid 2-43. Druk al-Ittihad, Sukabumi.

. (1937 - 1939). Tamsiyatul Muslimin Fii Tafsiri Kalami Robbil 'Alamiin Jilid 44-53. Druk Masduki, Sukabumi.

. (1931 - 1937). Tamsiyatul Muslimin Fii Tafsiri Kalami Robbil 'Alamiin Jilid 44-53. Druk Masduki, Sukabumi.

. (t.t). Rodlotul Irfan Fii Ma'rifatul Qur'an. Jilid 1 (Juz 115). Sukabumi.

. (t.t). Rodlotul Irfan Fii Ma'rifatul Qur'an Jilid 2 (Juz 1630). Sukabumi.

. (t.t). Qowaaniinu ad-Diiniyyah wa ad-Dunyaawiy- yah fii Bayaani Umuri aZ-Zakaati wa al-Fitrah. Sukabumi: Al-Ittihad.

. (1930). Tadzkiratu ath-Thaalibiin Fii Bayaani Sunniyati atTalqiin. Bogor: Kantor cetak Ihtiar. 
. (1928). Tasyqiiqu al-Auham Fii Rad'i 'Ani ath-Thagaam. Tanah Abang Betawi: Kantor Cetak Sayyid Yahya bin Utsman.

. (1928). Al-Mufhimaatu Fii Daf 'i al-Hayalaati. Tanah Abang Weltepreden Batawi: Kantor cetak Sayyid Yahya bin Ustman.

. (1928). Tahdziiru al-'Awaami Min Muftarayaati Cahyaa Islaami. Tanah Abang Weltepreden Batawi: Kantor cetak Sayyid Yahya bin Ustman.

. (1928). Silaahu al-Baasil Fii adh-Dhorbi 'Alaa Tazaahiiqu al-Baathil. Tanah Abang Weltepreden Batawi: Kantor cetak Sayyid Yahya bin Ustman.

. Tanbiihu al-Hairaan Fii Tafsiiri Suurati ad-Dukhaan.

. Kasyfu Sa'aadati Fii Tafsiiri Suarati al-Waqi'ah.

. Hidayaatu al-Quluubi ash-Shibyaani Fii Fadloo'ili Suurat Tabaarok al-Mulku Mina al-Qur'an.

. (t.t.). al-Quluubi al-Mu'miniin Fii Tafsiiri Kalimati Suraati Yaasiin. Tanah Abang, Batavia: Kantor Cetak Sayyid Yahya.

. (t.t.). Al-Mathlabu al-Asnaa Fii al-Asmaa'u al-Husnaa. Mr.C. Batavia: Druk “Djatinegara”.

. (1931). Hidaayatu al-Baarii Fii Bayaani Tafsir Boekhori, Nomor 2. Batavia Centrum: Toko Kitab Harun bin Ali Pakojan.

. (1931). Hidaayatu al-Baarii Fii Bayaani Tafsir Boekhori, Nomor 3. Batavia Centrum: Toko Kitab Harun bin Ali Pakojan.

. (1931). Majma'u al-Fawaaid Fii Tafsiiri Qowaa'idi al'Aqooid. Batavia: Kantor Cetak Harun bin Ali Pakojan.

. (t.t.). Tahdziiru al-Afkaar Mina al-Ightiraar Bidlalaalati waftiraayaati Tashfiyati al-Afkaar. Soekaboemi: Kantor Cetak al-Ittihad. 
. (1941). Al-Kalimaatu al-Mubayyinah Fii Qosiidati Ibnu Hujjah. Batavia: Kantor Cetak Sayyid Ali al-Idrus Karamat.

. (t.t.). At-Tanbiihu al-Maahir Fii al-Mukhaalit wa alMujaawir. Sukabumi: Druk "Masdoeki”.

. (1929). As-Siraaju al-Wahaaj Fii al-Israa wal Mi'raaj. Sukabumi: De Volwegh.

. (t.t.). Al-Jaauharotu al-Mardliyyah Fii Mukhtashoori alFuruu'i asy- Syaafi'iyyah. Karamat, Batavia: Kantor Cetak Sayyid Ali al-Idrus.

. Al-Fiqhu al-Akbar Karangan Imam Hanafi.

. (t.t.). Al-Muthahhirat Mina al-Mukaffiraat Typ “ Insulinde

"Sukabumi

. (1932). Hilyatu as-Shibyaan Fii bayaani Shaumi Ramadhaan. Batavia Karamat: Al-Ittihad Tanah Tinggi Poncol.

. (1953). Siraaju al-Afkaar Fiimaa Waroda Min Adzkaari alLaili wa an- Nahaari. Cianjur: Percetakan “ al-Ishlah “.

. (t.t.). Tamsyiyatu ad-Daraari (Risalah Ibrahim Bajuri). Sukabumi: De Volwegh.

. (1933). Dua Nabi Ibrahim 'Alaihi salaam. Batavia Centrum: Kantor Cetak Al-Ittihad.

. (t.t.). Al-Kawaakibu ad-Duriyyah Fii al-Ad'iyyati anNabawiyyah. Kantok Cetak Sayyid Yahya Tanah Abang, Batavia.

. (1933). Hilyatu al-'Aqli wa al-Fikri Fii Bayaani Muqtadliyyati asy-Syirki wa al-Kufri. Tanah Tinggi, Batavia: Al-Ittihad.

Sukabumi.

(t.t.). Mukhtaaru ash-Sholawaati. Gunungpuyuh 
. (t.t.). Duruusu an-Nahwiyyah Fii Kaifiyatu Tadriis alJurmiyyah. Tanah Tinggi, Batavia Karamat: Al- Ittihad. al- Mursaliin.

. (t.t). Daliilu as-Sa'iriin Fii Fadhli ash-Sholaati 'Ala Sayyidi . (t.t.). Hidayaatu al-Adzkiyaa Ilaa Thoriiqoti al-Auliyaa Li Syeikh Zainuddin Ibnu Ali al-Maburi. Tanah Abang, Batavia: Kantor Cetak Syyid Yahya.

. (1929). Tahdziiru al-`Awaam Min Muftariyati Cahya Islam. Batawi: Kantor Cetak Harun bin Ali Pakojan.

. (1931). Siraaju al-Ummati Fii Khosho'ishi al-Jum'ah. Batawi: Kantor Cetak Harun bin Ali Pakojan.

. (1932). Tauhiidu al-Muslimiin wa 'Aqaaidu al-Muminiin. Batawi: Kantor Cetak Harun bin Ali Pakojan.

. (t.t.). Tauhidoel - Moelimien Wa 'Aqoidoel- Moe'minien: Tiga Puluh tiga Faaidah (Bahasa Indonesia). Soekaboemi: Drukk. AlIttihad.

. (1942). As-Silaahu al-Mahiyyah Li Thariqa al-Firqa alMubtada'iyyah. Sukabumi: Pesantren Syamsul'Ulum Gunung puyuh.

. (1942). Hidayatu as-Shomad Fii Bayaani Matni al-Zubad. Sukabumi: Pesantren Syamsul’Ulum Gunungpuyuh.

. (t.t.). Tafriihu Shuduuri al-Mu'miniin Fii Maulidi Sayyidi al Mursaliin. Sukabumi: Pesantren Syamsul'Ulum Gunungpuyuh. . (t.t.). Misbahul Falaah Fii Arraadi al-Masaa'i wa ash-Shabahi. Sukabumi: Pesantren Syamsul'Ulum Gunungpuyuh.

Sukabumi, t.t.

Iiqaadlu al-Himam Fii Ta'liiqi al_hikam. Kutamas, 
. (2011). Miftahu al-Ginaa Mina al-Qahthi wa al-'Anaa. Sukabumi: Pesantren Syamsul 'Ulum Gunungpuyuh.

. (t.t.). Mandlomatu ar-Rijaal Li Sayyidii 'Ali Zainal Abidiin. Sukabumi: Pesantren Syamsul’Ulum Gunungpuyuh.

. (1930). Taaju al-Mafaahir Fii Tarjamati Tafriihu al-Khaathir Fii Manaaqibi as-Sayyidi Abdul Qaadir. Batawi: Kantor Cetak Harun bin Ali Pakojan.

. (1929). Al-Adawiyyati asy-Syaafiyyah Fii Bayaani Shalati al-Haajati wa al-Istikhaarati wa Daf 'i al-Karabati.

. (t.t.). Qolaa'idu ad-Dirari Fii bayaani 'Aqodi al-Jauhar. Batavia: Kantor Cetak Sayyid Yahya Tanah Abang.

. (t.t.). Siraaju al-Adzkiyaa Fii Tarjamati al-Azkiyaa.

. (t.t.). Tamsyiyatu al-Wildaan Fii Tafsiiri al-Qur'an.

. (t.t.). Lu Lu un-Nadhiid Fii Masaili at-Tauhid. As-Suyuufu ash-Shoorimah Fii ar-Roddi 'Alaa al-Fatawaa al- Baathilah28 Rabi'ul Akhir 1348 H/3-10-1929 M

. (1928). Al-Mufhimat Fii Daf 'i al-Khoyalaat Kancet. Batawi: Sayyid Utsman bin Yahya.

. (1928). Silaahu al-Baasil Fii adh-Dhorbi ‘Alaa Tazaahiiqu al-Bathiil. Batawi: Sayyid Utsman bin Yahya.

. (t.t.). Fathu al-Muqollatain Fii Bayaani Shihhatu alJum'atain. Sukabumi: Kantor Cetak “ al-Ittihad.

. (t.t.). Qowaiinu ad-Diniyyah wal ad-Dunyawiyyah Fii Umuuri az- Zakaati wa al-Fitrah. Sukabumi: Kantor Cetak " al-Ittihad”. . (t.t.). Siraaju al-Mu'miniin Fii Ad'iyati Surah Yaasiin. Pesantren Syamsul’Ulum Gunungpuyuh Sukabumi. 
. (1924). Jawaahiru al-Bahiyah Fii Adaabi al-Mar'ah alMutajawwijah. Batawi: Kantor Sayyid Abdullah bin Sayyid Utsman.

. (t.t.). Miftahu al-Jannah Fii Bayaani Ahli Sunnah wal Jama'ah. Sukabumi: Kantor Cetak al-Ittihad.

. (1933). Falhoir Kasab al-Ikhtiyar No.29 Desember Tahun 1933

. (t.t.). Nurul Yaqiin. Batavia: Kantor Cetak al-Ittihad Tanah Tinggi.

. (1935). Mindloratu al-Islam wa al-Iimaan. Sukabumi: Kantor Cetak al-Ittihad.

. (t.t.). Bahru al-Madad Fii Tarjamati Ayyuha al-Walad. Bogor: Percetakan "Sukma Raf".

. (1916). Hilyatu al-Iimaan Fii Fadhilati Qiroati al-Qur'an. Batawi: Kantor Cetak Sayyid Abdullah.

Barjanjii. . Tashiilu al-Maroojii Fii Tarjamati Maulid an-Nabii al. (1931). Hidaayatu al-Baarii Fii Bayaani Tafsir Boekhori, Nomor 1. Batavia Centrum: Toko Kitab Harun bin Ali Pakojan.

Saleh, M. (2016). K.H. Ahmad Sanusi : Pemikiran dan Perjuangannya dalam Pergolakan Nasional edisi pertama, cetakan keempat. Tanggerang Selatan: Jelajah Nusa.

https://en.wikipedia.org/wiki/Usman_bin_Yahya Diakses pada hari sabtu 06 Oktober 2018, pukul 03.38 WIB.

https://id.wikipedia.org/wiki/ Christiaan_ Snouck_Hurgronje. Diakses pada hari sabtu 06 Oktober 2018, pukul 03.38 WIB 
KH. Ahmad Sanusi dan Karya-Karyanya:

ISSN: $1858-2125$

Khasanah Literasi Ilmu-Ilmu Ajaran

Islam di Nusantara (Munandi Saleh) 